Margolies, M. P. (1951). Medicine (Baltimore), 30, 357

Marsden, P. D., and Blackman, V. (1964). E. Afr. med. 7., 41, 305

Mason, V. R. (1922). 7. Amer. med. Ass., 79, 1318.

Miall, W. E., Milner, P. F., Lovell, H. G., and Standard, K. L. (1967). Brit. F. prev. soc. Med., 21.45

Neel, J. V. (1950). Cold Spr. Harb. Symp. quant. Biol., 15, 141.

Paton, D. (1961). Arch. Ophthal., 66, 90.

Paton, D. (1962). Arch. Ophthal., 68, 627.

Raper, A. B. (1950). f. trop. Med. Hyg., 53, 49

Saas, M., and Spear, P. W. (1958). F. Lab. clin. Med., 51, 926.

Shaper, A. G., and Shaper, L. (1958). E. Afr. med. F., 35, 647.

Shubin, H., Kaufman, R., Shapiro, M., and Levinson, D. C. (1960). Amer. F. Cardiol., 6, 875.

Singer, K., Chernoff, A. I., and Singer, L. (1951). Blood, 6, 413.

Sydenstricker, V. P. (1924) Sth. med. f. (Bgham, Ala.), 17, 177.

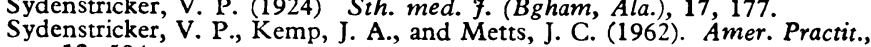
13, 584.

Trowell, H. C. (1945). E. Afr. med. F., 22, 34.
Trowell, H. C., Raper, A. B., and Welbourn, H. F. (1957). Quart. F. Med., 26, 401 .

Uzsoy, N. K.' (1964). Amer. f. Cardiol., 13, 320.

Vandepitte, J. M. (1952). Brit. med. F., 1, 920.

Vandepitte, J. M. (1952). Brit. med. F., 1, 920.

Vandepitte. J. M. (1955a), Docum. Med. geogr. trop. (Amst.), 7,

Vandepitte, J .M., and Pieters, G. (1952). Ann. Soc. belge. Méd. trop., 32, 281 .

Walshe, M. W., and Milner, P. F. (1967). West Indian med. F., 16, 10.

Washburn, R. E. (1910-11). Virginia Med., semi-monthly 15, 490.

Welbourn, H., and Raper, A. B. (1954). Brit. med. F., 1, 1440.

Went, L. N., and MacIver, J. E. (1958). Lancet, 2, 824.

Went, L N and MacIver, J E (1961) Blood, 17, 166.

Winsor, T., and Burch, G. E. (1944). Hum. Biol., 16, 99.

Winsor, T., and Burch, G. E. (1945a). Arch. intern. Med., 76, 47.

Winsor, T., and Burch, G. E. (1945a). Arch. intern. Heart F., 29, 685

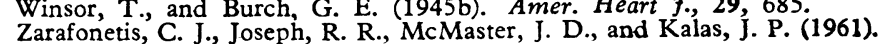
7. Lab clin. Med., 57, 600 .

\title{
Clinical Use of Atrial Pacing Test in Angina Pectoris
}

\author{
RAPHAEL BALCON,* M.B., M.R.C.P.; WILLIAM C. MALOY,* M.D.; EDGAR SOWTON,* M.A., M.D., M.R.c.P.
}

Gummary : Atrial pacing can be used as a safe test in $\checkmark$ the assessment of patients with angina pectoris. The results are useful in clinical judgements, and this method of investigation may be indicated for patients in whom the diagnosis of angina pectoris is in doubt or who are being considered for surgical treatment of ischaemic heart disease.

\section{Introduction}

The difficulties in evaluating patients with angina pectoris are well known and are assuming greater importance with the increasing application of surgical techniques of revascularization of the heart. Since angina is a symptom, it cannot be evaluated objectively, and clinical interpretation of the state of the disease may be greatly influenced by a placebo response or by wide variations in effort tolerance from day to day. This spontaneous variation may also confuse the interpretation of exercise tests, while electrocardiographic (E.C.G.) changes as an endpoint do not always correlate with the time of onset of pain. The purpose of this paper is to describe our clinical experience with the use of an atrial pacing test over a period of one year. This test relies on the temporary production of an artificial supraventricular tachycardia by pacing from the right atrium of resting patients.

\section{Methods}

The technique has been described in detail elsewhere (Sowton et al., 1967), but it essentially depends on the percutaneous passage of a bipolar pacing electrode from a peripheral vein to the right atrium. The heart rate is then controlled by an external adjustable pacemaker and the systemic pressure is simultaneously recorded from a very fine $(1 \mathrm{~mm}$.) Teflon catheter introduced by the Seldinger technique. The heart rate is increased in increments until the earliest detectable sensation of substernal oppression is reported by the patient, and the tension-time index at this point is calculated from the pressure trace. This tension-time index has been shown to be a highly repeatable measure of the " angina threshold," provided there is no sudden increase in heart size (Sowton et al., 1967). We suggest that measurements of the angina threshold in this way may be useful in following the progress of individual patients over a period of time, but do not claim that valid

* Institure of Cardiology and the National Heart Hospital, London W.1. comparisons can be made between different patients. All the manifestations of cardiac ischaemia, including the substernal oppression, can be very rapidly reverted to the control state by reducing the pacing rate. The entire test procedure can be performed on an outpatient basis, several confirmatory measurements of angina threshold being made within 60 minutes.

\section{Results}

The detailed haemodynamic and E.C.G. findings at the onset of pain and during treatment with various anti-anginal drugs have already been reported both by ourselves and by others (Sowton et al., 1967 ; Lau et al., 1967b ; Friesinger et al., 1967 ; Frick et al., 1968). The first 42 patients studied had a clear clinical history of angina, and 39 of them had ischaemic changes on the E.C.G. They were investigated as part of an assessment for revascularization surgery, and in addition had the usual full clinical and radiological examination and often went forward to selective angiography by the Mason Sones technique. The Table shows the results of the atrial pacing test in these patients grouped according to the clinical severity of their disease.

Results of Atrial Pacing Test

\begin{tabular}{|c|c|c|c|c|c|c|c|}
\hline \multirow{2}{*}{$\underset{\text { Grade }}{\text { Clinical }}$} & \multicolumn{3}{|c|}{$\begin{array}{c}\text { No. of } \\
\text { Patients }\end{array}$} & \multirow{2}{*}{$\underset{\mathrm{Age}}{\text { Mean }}$} & \multicolumn{2}{|c|}{$\begin{array}{l}\text { Angina } \\
\text { Induced }\end{array}$} & \multirow{2}{*}{$\begin{array}{l}\text { Percentage of } \\
\text { Group with } \\
\text { Induced } \\
\text { Angina }\end{array}$} \\
\hline & $\mathbf{M}$ & $\mathbf{F}$ & Total & & Yes & No & \\
\hline $\begin{array}{l}1 \\
2 \\
3 \\
4\end{array}$ & $\begin{array}{r}5 \\
15 \\
11 \\
5\end{array}$ & $\begin{array}{l}1 \\
1 \\
1 \\
3\end{array}$ & $\begin{array}{r}6 \\
16 \\
12 \\
8\end{array}$ & $\begin{array}{l}50 \cdot 2 \\
54 \cdot 4 \\
52 \cdot 2 \\
54 \cdot 4\end{array}$ & $\begin{array}{r}1 \\
11 \\
11 \\
8\end{array}$ & $\begin{array}{l}5 \\
5 \\
1 \\
0\end{array}$ & $\begin{array}{r}17 \\
69 \\
92 \\
100\end{array}$ \\
\hline
\end{tabular}

Group 1 : Pain occurs only occasionally, on exceptional effort or emotion-for example, hurrying uphill.

Group 2: Pain occurs during ordinary activity; walking is restricted to 200 yards (180 metres) at normal pace.

Group 3 : Pain after 50 yards (46 metres) or less.

Group 4 : Pain at rest.

Pain was produced during atrial pacing in only one patient in group $1(17 \%), 11$ out of 16 had pain in group $2(69 \%), 11$ out of 12 in group $3(92 \%)$, and all in group $4(100 \%)$.

From these results it was felt that the test might have diagnostic significance in cases where there were atypical features and diagnosis was in doubt. The first two of the following case histories are taken from the original series of 42 patients ; the other two are of patients subsequently tested. 


\section{Case Histories}

Case 1.-A 52-year-old man had suffered for 10 years from ischaemic heart disease with three episodes of myocardial infarction. Following the last attack in January 1967 he had severe incapacitating angina which occur red on the least exertion and frequently at rest. The E.C.G. at this time showed right bundle-branch block and evidence of old posterior infarction and anterolateral ischaemia. Atrial pacing indicated an angina threshold at a tension-time index of 2,800 units. Selective coronary angiography revealed a completely occluded right coronary artery and a probable complete occlusion of the left anterior descending coronary artery. Both internal mammary arteries were implanted into the left ventricle. There was no clinical improvement for the first four months after operation, and a follow-up atrial pacing study showed the angina threshold at this time was unchanged $(2,800$ units). When seen nine months after operation there had been considerable clinical improvement and he could walk 2 miles $(3 \mathrm{~km}$.) with the aid of trinitrin. The E.C.G. showed considerable remission of the ischaemic changes. A further assessment of the angina threshold showed that it had increased to 3,400 units. This case illustrates the good correlation between measured angina threshold and clinical course.

Case 2.-A 51-year-old man had had chest pain for seven years. The symptoms gradually became more severe until at the time of assessment he was incapacitated by exertional pain. Many physicians had difficulty in deciding whether he was experiencing cardiac pain, because of many atypical features and because of obvious additional functional symptoms. Repeated E.C.G.s showed only slight nonspecific T-wave changes, and exercise tests were not helpful. Atrial pacing indicated a clear anginal threshold at a tension-time index of 2,700 units. Selective coronary angiography was then performed and stenoses of both right and left anterior descending coronary arteries were found. An internal mammary implant and a free omental graft to the left ventricle were performed. This case illustrates the use of the pacing test as an aid in the diagnosis of angina when the patient has an atypical history, with functional symptoms.

Case 3.-A 40-year-man suffering from familial hypercholesterolaemia had two relatives who had died at an early age from cardiovascular disease. The patient had had two documented attacks of coronary thrombosis at the ages of 37 and 38 . Since then he has had severe chest pain both on exertion and at rest. The pain was atypical in that it was always prolonged. He was extremely anxious because of his family history and because of the past infarctions. The E.C.G. showed evidence of posterior infarction. No angina was produced by atrial pacing despite reaching a rate of $160 / \mathrm{min}$. and a tension-time index of 4,250 units. Selective coronary angiography revealed diffuse irregularities of the coronary arteries with a marked stenosis in the right coronary artery but good distal filling. It was concluded that this patient, despite diffuse coronary artery disease, did not have ischaemic cardiac pain at the time of investigation, and this conclusion was borne out by an exercise test. This case illustrates the value of the test in excluding anginal pain in a man with coronary artery disease.

Case 4.-A 59-year-old man had had chest pain on effort, with radiation to the left arm, for six years; trinitrin or resting relieved the pain. The pain became progressively more severe until he had to give up work two years ago. The E.C.G. showed incomplete right bundle-branch block with no evidence of infarction. Atrial pacing did not provoke pain at any time, despite heart rates up to $150 / \mathrm{min}$. This negative finding was confirmed by selective coronary angiography, which showed only possible minimal disease at the origin of the circumflex artery with all other vessels normal. Since the diagnosis of angina became untenable the patient has improved considerably and will return to work. In this case the atrial pacing test was very valuable in excluding angina in a man with severe and unsuspected cardiac neurosis.

\section{Discussion}

The test has proved very safe and there have been no complications apart from minor bruising around the site of the arterial puncture. On theoretical grounds the production of an artificial tachycardia will increase the myocardial oxygen consumption, and the tension-time index is used here as an approximate indication of these changes. Anginal pain is felt when the coronary blood flow is unable to meet this oxygen demand, and in the atrial pacing test this point can be easily identified.
Since the patient as a whole is not exercising, there is no muscle pump to increase venous return from the periphery and there is no increase in cardiac output as the rate is increased. In effect, this test exercises the heart without exercising the patient.

In patients with relatively minor disease a very considerable increase in the heart rate may be required to produce angina. We have imposed a maximum pacing rate of approximately 160 beats/min. during the test, and this may explain why some patients accepted as having angina clinically did not experience pain during the procedure. It is possible that these patients represent false-negative results, but we see no other way of confirming the presence or absence of angina. The occurrence of pain correlated well with the clinical evaluation (see Table), being produced in only $17 \%$ of group 1 patients but in $100 \%$ of group 4, and we feel that this confirms the view that pain did not occur because the pacing rate was not fast enough.

Case 3 would have been placed in group 4 had the atypical features in the history not cast doubt on the diagnosis. We felt that the absence of pain despite increasing the heart rate to $160 / \mathrm{min}$., together with appearances on coronary angiography, justified the conclusion that his pain was not then anginal. In a similar way Case 4 would be in group 4, and thus pain during the test was confidently expected. We felt that the absence of pain, supported subsequently by an almost normal coronary angiogram, was sufficient to reject the previous diagnosis of severe angina. Though it is not possible by this or any other test positively to exclude the diagnosis of angina, our test results were incompatible with the clinical history, and indicate that their symptoms were not those of angina.

Our finding that an anginal threshold can be identified in most patients by atrial pacing agrees well with observations during exercise-induced angina made by Robinson (1967). Lau et al. (1967b) have also shown that E.C.G. changes of ischaemia can be produced by right atrial pacing at rest in patients with angina. We have shown that the angina threshold is the same whether produced by atrial pacing or by exercise (Balcon, 1968). Lau et al. (1967a) have reached a similar conclusion. We have found the test to be a simple and safe method of assessing patients, and a knowledge of the tension-time index at which symptoms first appear has become a valuable piece of information in deciding on clinical treatment.

Atrial pacing provides complementary information to coronary angiography and is not intended to replace other methods of evaluation. However, it can be rapidly performed on an outpatient basis and may be helpful in excluding a diagnosis of angina. We suggest that this method of investigation may be indicated in the following circumstances: (1) evaluation of patients in whom functional symptoms are confusing the history, (2) preoperative assessment and postoperative follow-up of patients treated by internal mammary implants or other revascularization procedures, and (3) investigation of patients in whom electrocardiographic or physical signs seem incompatible with the history.

There are further possible indications, such as the routine measurements of the anginal threshold to determine the progress of the disease, but our experience is still too limited for these to be clarified at present.

We would like to thank our colleagues for kindly referring patients. Revascularization procedures were performed by $\mathbf{M r}$. D. N. Ross.

\section{REFERENCES}

Balcon, R. (1968). Unpublished data.

Frick, M. H., Balcon, R., Cross, D., and Sowton, E. (1968). Circulation, 37,160 .

Friesinger, G. C., Conti, C. R., and Pitt, B. (1967). Circulation, 36, Suppl. No. 2, p. 115

Lau, S. H., Haft, J. I., Cohen, S. I., Helfant, R. H., Young, M. W. and Damato, A. N.' (1967a). Circulation, 36, Suppl. No. 2, p. 169. Lau, S. H., Haft, J. I., Cohen, S. I., Kinney, M. J., Helfant, R. H., and Damato, A. N. (1967b). Clin. Res., 15, 212.

Robinson B. F. (1967). Circulation, 35, 1073.

Sowton, G. E., Balcon, R., Cross, D., and Frick, M. H. (1967). Cardiovasc. Res., 1, 301. 